\title{
Development of an Engineer Operation Aimed at the Reduction of Atmospheric Dust Pollution in the Decommissioning of Iron-Ore Treatment Waste
}

\author{
Igor Suprun ${ }^{1 *}$, Vladimir S. Kuznetsov' ${ }^{1}$, Andrey V. Ivanov ${ }^{1}$ \\ 1 Saint-Petersburg Mining University, 21st Line Vasilevsky Ostrov, 2, 199106, Saint Petersburg, Russia \\ * Corresponding author's e-mail: igor_suprun@mail.ru
}

\begin{abstract}
This work covers the pollution of the atmosphere during the work of the Mikhailovsky Mining and Refining Facility which is located within $100 \mathrm{~km}$ from the city of Kursk, in the city of Zheleznogorsk. Over the past few years in the whole world, the anthropogenic activity, connected mainly with the locations of mineral production and those of mineral treatment and processing, has become increasingly dangerous for the natural environment. Resource development in open pits causes the formation of inorganic dust. The dust is released into the atmosphere at all stages of the enterprise's technical process. The principal sources generating inorganic dust during open mining of iron deposits include: blasting operations in an open pit, the work of transfer points, the enrichment process at a factory, pellet firing as well as dusting from the surfaces of stock dumps and dry tailings beaches.
\end{abstract}

Keywords: reduction, dust pollution, decommissioning, iron-ore waste

\section{INTRODUCTION}

A large quantity of inorganic dust of this facility reaches the environment from the deposit of treatment waste. In the process of stocking up treatment waste, dry beaches form on a tailings dump which occupy from 25 to $30 \%$ of the area and actively release dust into the atmosphere during the summer season [Strizhenok, 2016]. The dust blown away by the wind of the surface of the tailings dump disperses in the atmosphere and subsequently falls on a soil surface by way of gravitational settling or fallout, which leads to the formation of secondary pollution (in particular, by the heavy metals contained in dust) in a soil covering [Strizhenok, 2017]. The iron-ore dust negatively impacts the production capacity of agricultural fields because of soil pollution by various metals. Besides soil pollution, there is also an alteration of the morphological structure of the soil profile and a change of landscape [Volkodaeva, 2017].
During the treatment process, the formation of a concentrate and treatment rejects (tails of wet magnetic separation) takes place in the course of the extraction of iron-ore materials. The waste volume makes up to $40-60 \%$ from the volume of the treated material.

The chemical makeup of such waste is formed exclusively from the landscape forming elements: $\mathrm{Si}$ (silicon), Al (aluminium), Fe (iron), $\mathrm{Ca}$ (calcium), Mg (magnesium), K (potassium), $\mathrm{Na}$ (sodium), O (oxygen), notably in a bound oxidised form (carbonates, oxides, silicates).

\section{MATERIALS AND METHODS}

As practised elsewhere in the world, the following methods of dust suppression to reduce air dust pollution are used:

1. Physicochemical fixing methods consist in changing the properties of the surface layer of the aggraded material by stabilisation of dust-forming surfaces. They are irrigated with 
various hydraulic systems which may contain binding materials.

Currently, the physicochemical methods of dust reduction are in a more frequent use than others. It allows us to detect the main methods: hydrotechnical method and the fixing of a dust-forming surface with polymers, organic and inorganic substances of the surface [Lychagin, 2007].

a) Hydrotechnical method is the simplest and the most accessible; it comes down to a continuous hydration of dust-forming surfaces with irrigation systems. The effectiveness of this method reaches approximately $50-60 \%$, which, in most cases, is enough to reduce the dust concentration to a permissible exposure limit at the boundary of the sanitary protection zone [Nemirovsky, 2016].

b) The use of physicochemical fixing methods of dust-forming surfaces is a promising direction. The basis of these methods is binding materials. Their application is the foundation of multiple research works [Tcvetkov, 2017].

2. Biological methods of reduction of dust emissions consists in creating anti-erosion plantation allowing to anchor the surface of beaches by way of planting higher vegetations. These methods can be classified into two groups: biogenic and biocenotic.

3. Technological methods of dust formation prevention indirectly promote the reduction of the environmental footprint made on the atmosphere in the zone of operation of enrichment plants: 1) development of the way of storage for enrichment rejects, so that particle lifting is minimal; 2) creation of low-waste technologies, as a result of which a complex processing of raw materials is carried out and an environmental footprint is consequently reduced [Nemirovsky, 2016]; 3) elimination of waste.

4. A mechanical method can be classified into two groups: 1) a complete surface cover with a non-dusting material: road metal, gravel, pellets based on clay, clay loam, etc. The thickness of the coat applied must be no less than $0.15 \mathrm{~m}$ [Lychagin, 2007]; 2) arrangement of man-made obstacles, forest shelterbelts, etc.

The mechanical methods of the dust discharge reduction from the surfaces of man-made massifs are preferable under the conditions of dry as well as a rigorous climate, due to the complexity of application of irrigation systems under such conditions or the creation of vegetation cover [Tcvetkov, 2017].

\section{RESULTS AND DISCUSSIONS}

In order to establish the composition of the enrichment rejects, the samples from the surface of the tailings dump were collected and a qualitative and quantitative chemical analysis of the composition of enrichment rejects on optical emission simultaneous spectrometer with inductively-coupled plasma ICPE-9000 was carried out - see Table 1 [M-MVI-80-2008].

Following the results of the qualitative and quantitative analysis on ICPE-9000, one can make a conclusion about a high content of iron and silicon in waste samples; therefore, these elements are also present in the dust excreted from the surface of the tailings dump.

Small particles have the worst impact on the human body. Tiny particles of dust with the size of 1 to $5 \mu \mathrm{m}$ infiltrate into the lungs. The particles of less than 1-3 $\mu \mathrm{m}$ in diameter, which can reach pulmonary alveoli, are the most harmful. As a rule, these particles comprise $40-70 \%$ of suspended particular matter. When reaching the lungs, the dust settles there and, as time passes, turns the lungs into a fibrous tissue which does not participate in the exchange process between oxygen and carbon dioxide.

For grain-size analysis of dry waste samples, a laser particle analyser for particle size distribution Horiba LA-950, which is intended for measuring dispersive parameters (particle sizes and the functions of particle size distribution according to their sizes) of suspended mixtures, emulsions and powdered materials, was used. As a result of the grain-size analysis, it was established that in the selected samples, the content of particles with the fraction size of $1-5 \mu \mathrm{m}$ constitutes approximately $25-30 \%$ of the total fraction composition of the sample [Hygienic standards 12536-79].

During the summer of 2017, measurements of air dust content were taken [GOST P 56059-2014] with the help of dust counter DustTrak 8533 of the company in 34 points at various distances from the tailings dump, at a height of about $1.6 \mathrm{~m}$ above ground. The results of these measurements are presented in Table 2. 
Table 1. Component content (ppm) in the waste samples based on the results of the qualitative analysis on ICPE-9000

\begin{tabular}{|c|c|c|c|c|c|}
\hline \multicolumn{6}{|c|}{ Sample 01} \\
\hline & $\mathrm{Ca}$ & $\mathrm{Fe}$ & $\mathrm{Si}$ & $\mathrm{Mg}$ & $\mathrm{Mn}$ \\
\hline$X_{\text {mid, }} \mathrm{mg} / \mathrm{l}$ & 74.8 & 1.94 & 1.320 & 383 & 32.4 \\
\hline $\mathrm{X}_{\mathrm{i}}, \mathrm{mg} / \mathrm{kg}$ & 2680 & 194000 & 131050 & 3680 & 307 \\
\hline$\%$ & 0.268 & 19.4 & 13.105 & 0.368 & 0.031 \\
\hline \multicolumn{6}{|c|}{ Sample 02} \\
\hline & $\mathrm{Ca}$ & $\mathrm{Fe}$ & Si & $\mathrm{Mg}$ & $\mathrm{Mn}$ \\
\hline$X_{\text {mid, }} \mathrm{mg} / \mathrm{l}$ & 140 & 2.53 & 1.83 & 397 & 34.6 \\
\hline $\mathrm{X}_{\mathrm{i},} \mathrm{mg} / \mathrm{kg}$ & 9200 & 253000 & 182050 & 3820 & 329 \\
\hline$\%$ & 0.92 & 25.3 & 18.205 & 0.382 & 0.033 \\
\hline \multicolumn{6}{|c|}{ Sample 03} \\
\hline & $\mathrm{Ca}$ & $\mathrm{Fe}$ & $\mathrm{Si}$ & $\mathrm{Mg}$ & $\mathrm{Mn}$ \\
\hline$X_{\text {mid, }} \mathrm{mg} / \mathrm{l}$ & 114.2 & 2.370 & 1.520 & 391 & 33.6 \\
\hline$X_{i}, \mathrm{mg} / \mathrm{kg}$ & 6620 & 237000 & 151050 & 3760 & 319 \\
\hline$\%$ & 0.662 & 23.7 & 15.105 & 0.376 & 0.003 \\
\hline
\end{tabular}

Table 2. Measurement data for air pollution in the location of tailings storage dump

\begin{tabular}{|c|c|c|c|c|}
\hline \multirow{2}{*}{ No. } & \multicolumn{2}{|c|}{ Coordinates } & \multirow{2}{*}{$\begin{array}{l}\text { Dust concentration, } \\
\mathrm{mg} / \mathrm{m}^{3}\end{array}$} & \multirow{2}{*}{$\begin{array}{l}\text { Distance from } \\
\text { dusting source, } m\end{array}$} \\
\hline & Longitude & Width & & \\
\hline 1 & 52.3303 & 35.5371 & 7.516 & 0 \\
\hline 2 & 52.3287 & 35.5444 & 4.125 & 600 \\
\hline 3 & 52.328 & 35.5052 & 4.521 & 500 \\
\hline 4 & 52.3259 & 35.51 & 4.321 & 500 \\
\hline 5 & 52.3224 & 35.5459 & 1.865 & 1300 \\
\hline 6 & 52.3251 & 35.5418 & 3.745 & 800 \\
\hline 7 & 52.3291 & 35.5513 & 1.548 & 1300 \\
\hline 8 & 52.3319 & 35.5537 & 1.196 & 1500 \\
\hline 9 & 52.3286 & 35.5577 & 1.112 & 2000 \\
\hline 10 & 52.3239 & 35.5568 & 1.198 & 2100 \\
\hline 11 & 52.319 & 35.5586 & 0.523 & 2600 \\
\hline 12 & 52.3165 & 35.5525 & 0.513 & 2200 \\
\hline 13 & 52.3195 & 35.5682 & 0.185 & 3600 \\
\hline 14 & 52.325 & 35.5699 & 0.209 & 3400 \\
\hline 15 & 52.3286 & 35.574 & 0.198 & 4000 \\
\hline 16 & 52.3143 & 35.5696 & 0.219 & 4000 \\
\hline 17 & 52.3196 & 35.5381 & 2.541 & 800 \\
\hline 18 & 52.3128 & 35.5464 & 0.663 & 1900 \\
\hline 19 & 52.3346 & 35.5841 & 0.171 & 5000 \\
\hline 20 & 52.3346 & 35.5774 & 0.162 & 4700 \\
\hline 21 & 52.3395 & 35.5992 & 0.211 & 5000 \\
\hline 22 & 52.3458 & 35.5969 & 0.183 & 4700 \\
\hline 23 & 52.3405 & 35.6063 & 0.151 & 5700 \\
\hline 24 & 52.3518 & 35.5878 & 0.263 & 3500 \\
\hline 25 & 52.3519 & 35.5762 & 0.541 & 2400 \\
\hline 26 & 52.3196 & 35.5052 & 1.826 & 1200 \\
\hline 27 & 52.3193 & 35.5255 & 1.235 & 900 \\
\hline 28 & 52.3123 & 35.5358 & 1.054 & 1500 \\
\hline 29 & 52.328 & 35.5338 & 7.429 & 0 \\
\hline 30 & 52.3315 & 35.5394 & 7.854 & 0 \\
\hline 31 & 52.3252 & 35.5308 & 5.214 & 300 \\
\hline 32 & 52.3273 & 35.517 & 5.154 & 350 \\
\hline 33 & 52.3291 & 35.5281 & 7.652 & 0 \\
\hline 34 & 52.309 & 35.5705 & 0.098 & 4500 \\
\hline
\end{tabular}




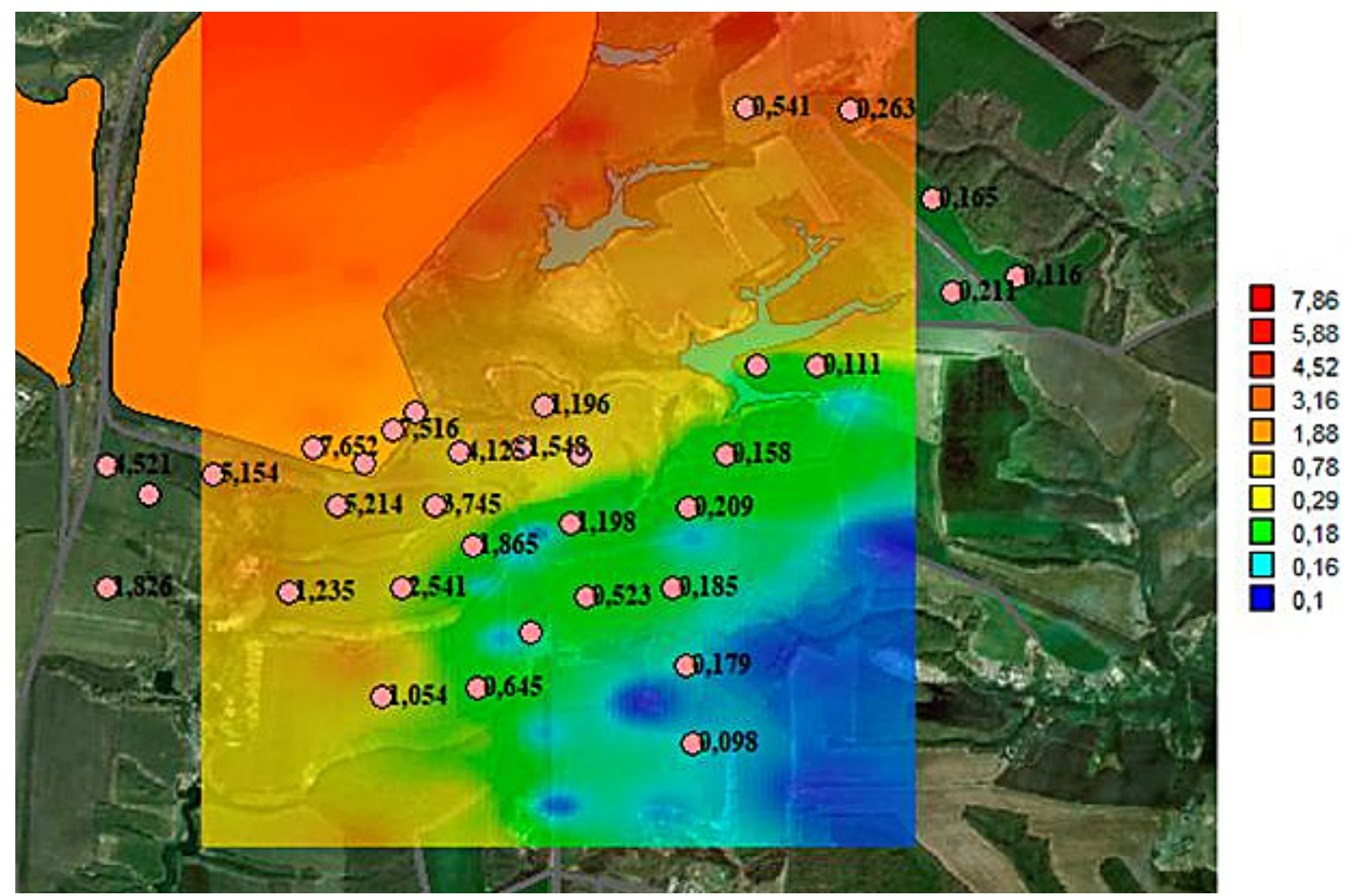

Figure 1. Visualisation of the concentration field of inorganic dust in the atmosphere

From the data analysis presented in the table, it follows that the inorganic dust guidelines [Hygienic Standard 2.1.6.3492-17] exceeded the allowable ratio by approximately $8-10$ times at a distance of $1 \mathrm{~km}$ from the source (sanitary protection zone).

In order to establish the surface of the air pollution, a simulation of the impact of dust was carried out in the MapInfo Professional programme.

MapInfo is a geographical information system (GIS) intended to gather, store, reflect, edit and analyse spatial data. With the usage of MapInfo programme, it was possible to the identify zones with high level dust pollution of the atmosphere in close proximity to the tailings storage site (tailings dump). The results of the simulation are presented in Figure 1.

The results of the simulation graphically reflect the level of the territory pollution by inorganic dust in the immediate vicinity of the tailings storage site on the territory of the mining and processing enterprise.

In order to irrigate large areas with a large irrigation radius and to achieve a maximal uniformity of liquid deposition on to a dust-forming surface, irrigation water (aerosol) guns were used.

Aerosol guns for dust suppression can work at the temperatures down to - 20 degrees. They can be developed further by adding the capacity to work in a snow mode to guarantee dust suppression in lower temperatures.

An aerosol gun is a device with a cylindrical body, inside which there are spraying nozzles (pulverisers), a diffuser and an air-screw fan. The range of liquid throw from the aerosol gun varies from 20-30 to 200 metres, which is a great advantage in comparison with the pulveriser system.

When a gun is located close to the surface, the so called "spreading" effect can be observed. In this case the subsidence of drops takes place due to a contact with the surface. The drops over the surface continue their movement without sedimentation. Due to an aerosol gun, the whole patch of the dry surface is irrigated, and not just several plots of the massif.

During the usage of aerosol guns for dust suppression, one needs to consider the direction and intensity of wind. When the direction of wind coincides with that of an irrigation jet, the flight distance of aerosol spray increases; however, in the case of an opposite wind direction, the spread of aerosol will be blocked and the effect of stabilisation of a dust-forming surface will be decreased. In such cases, the particles of dust will interact with the aerosol by means of adhesive power, which consequently will lead to their sedimentation.

Because of the high cost of aerosol guns, a stationary installation of guns along the perimeter 
of the tailings dump is not viable. Therefore, it is essential to develop the system of gun transportation along the perimeter. The best option will be the installation of a gun on a rail platform along which the aerosol gun will move together with a water cistern.

The platform houses an aerosol gun for dust suppression with a guiding device; compressor station; water pump; a motor drive for one axis of the platform; system control unit for receiving and processing the information; a diesel-electric power plant for power supply to the complex.

The maximum achievable speed of the plant is $23 \mathrm{~km} / \mathrm{h}$. The optimal speed can be calculated based on computation.

In order to optimise the performance of the plant, the development of different operational modes depending on weather conditions needs to be carried out. The data can be obtained from the monitoring systems of the production process. The key parameters include: temperature, wind speed, wind direction, depth of rainfall, etc.

The area of dust-forming surface of the tailings dump constitutes $300,000 \mathrm{~m}^{2}$. However, if we also consider an aggradation system, an additional $50,000 \mathrm{~m}^{2}$ is irrigated. The extension of the dust-forming surface available for the implementation of the irrigation system reaches $19 \mathrm{~km}$. The width of the dust-forming surface is 50 to 300 metres.

Summarising the results of the experiment, the required quantity of water for stabilisation of $1 \mathrm{~m}^{2}$ of the dust-forming surface is 3 litres, on average. Depending on weather conditions, dust emissions will cease for up to 7 hours. Under poor weather conditions (high temperature, high wind speed, the absence of rainfall), irrigation needs to take place every 2 hours.

It is proposed to use 2 aerosol guns with cisterns along the perimeter of $23 \mathrm{~km}$. The requirements for an aerosol gun - inclusion area:
$100-120 \mathrm{~m}^{2}$, capacity rate: no less than $100 \mathrm{l} / \mathrm{s}$. In this case, the optimal speed will be $3 \mathrm{~m} / \mathrm{s}$.

The operational efficiency of a dust suppressing facility is determined by means of correspondence of their technological parameters to a specific source of dust formation and a performance capacity of dust suppressing facilities. The problem of air dust removal under the conditions of technological processes, where the stretch of the source of dust removal and the volume of dust-loaded air are quite extensive, is particularly complex.

\section{CONCLUSIONS}

1. On the basis of the experiment data, it is possible to develop an irrigation system depending on the weather conditions.

2. The key operational modes of the system of irrigation by aerosol guns are presented in Table 3.

3. Under poor weather conditions (high temperature, high wind speed, lack of rainfall), the irrigation of dry beaches needs to take place every 2 hours.

4. If 2 aerosol guns are installed, irrigation of the whole perimeter will take 53 minutes. If there is 1 gun, the irrigation of the whole perimeter will take 1 hour 46 minutes. Taking into account the weather condition of relatively low wind speed during the course of the experiment, it is fair to assume that increasing this parameter will also increase the drying speed of tailings, as a consequence of which it will be necessary to carry out a repeated irrigation. Subsequently, conclusion should be drawn that the presence of 2 aerosol guns will be optimal for the object considered.

5. While implementing the proposed method for the tailings dump of the Mikhailovsky Mining and Refining Facility, it is possible to decrease

Table 3. Operational modes of the system of irrigation by aerosol guns

\begin{tabular}{|c|c|c|c|c|}
\hline \multirow{2}{*}{$\begin{array}{c}\text { Operation } \\
\text { mode }\end{array}$} & Air temperature, ${ }^{\circ} \mathrm{C}$ & Wind velocity, $\mathrm{m} / \mathrm{sec}$ & Rainfall & \multirow{2}{*}{ Irrigation mode } \\
\hline & $\geq 29$ & $\geq 9$ & - & Each 1 hour \\
\hline 1 & $22-29$ & $5-9$ & - & Each 3 hours \\
\hline 2 & $\leq 22$ & $\leq 5$ & - & Each 6 hours \\
\hline 3 & $\geq 27$ & $\geq 7$ & + & Each 3-4 hours \\
\hline 4 & $21-27$ & $5-7$ & + & Each 4-6 hours \\
\hline 5 & $\leq 21$ & $\leq 5$ & + & Each 12 hours \\
\hline 6 & &
\end{tabular}


the dusting of the tailings dump to the required safe standards. The proposed irrigation system has a large spraying range which will decrease the quantity of dust-forming dry beaches and increase the effectiveness of dust suppression.

\section{REFERENCES}

1. GOST P 56059-2014. Production environmental monitoring.

2. Hygienic standards 12536-79. Methods for laboratory determination of granulometric (grain) and micro aggregate composition.

3. Hygienic Standard 2.1.6.3492-17. Maximum admissible concentration of pollutants in atmospheric air of city and rural settlements.

4. Lychagin E.V., Sinitca I.V. 2007. Improvement of methods of fixing of the raising dust surfaces//the Mountain information and analytical bulletin. $-\mathrm{M}$ : MGGU, No. 8, 136-140.

5. M-MVI-80-2008. A technique of performance of measurements of a mass fraction of elements in tests of soils, soil and ground deposits by methods of atomic and issue and atomic and absorbing spectrometry. SPb: 2008.

6. Nemirovsky A.V. 2016. Development of a method of formation of the alluvial tailings dam steady against wind streams.: yew. Cand. Tech. Sci. (25.00.20), pp. 122.

7. Strizhenok A.V., Ivanov A.V. 2016. An advanced technology for stabilizing dust producing surfaces of built-up technogenic massifs during their operation. Power Technology and Engineering, 50(3), 240-243.

8. Strizhenok, A.V., Ivanov, A.V. 2017. Efficiency of Dust Suppression with Aerosol Guns-Fogging Machines with Air-and-Fluid Jets. Journal of Mining Science, 53(1), 176-180.

9. Tcvetkov P., Strizhenok A. 2017. Ecology-economical assessment of new reclamation method for currently working technogenic massifs. Journal of Ecological Engineering, 18(1), 58-64.

10. Volkodaeva M.V., Kiselev A.V. 2017. On development of System for Environmental Monitoring of Atmospheric Air Quality. Zapiski Gornogo Instituta, Vol. 227, 589-596. DOI: 10.25515/ PMI.2017.5.589. 